\title{
Biologging Physiological and Ecological Responses to Climatic Variation: New Tools for the Climate Change Era
}

\author{
Helen E. Chmura ${ }^{1,2}$, Thomas W. Glass ${ }^{3,4}$ and Cory T. Williams ${ }^{2,3 *}$ \\ ${ }^{1}$ Department of Neurobiology, Physiology and Behavior, University of California, Davis, Davis, CA, United States, ${ }^{2}$ Institute of \\ Arctic Biology, University of Alaska Fairbanks, Fairbanks, AK, United States, ${ }^{3}$ Department of Biology and Wildlife, University \\ of Alaska Fairbanks, Fairbanks, AK, United States, ${ }^{4}$ Arctic Beringia Program, Wildlife Conservation Society, Fairbanks, AK, \\ United States
}

\section{OPEN ACCESS}

Edited by:

Thomas Wassmer,

Siena Heights University,

United States

Reviewed by:

Daniela Campobello,

Università degli Studi di Palermo, Italy

Simon Verhulst,

University of Groningen, Netherlands

Graeme Clive Hays,

Deakin University, Australia

${ }^{*}$ Correspondence:

Cory T. Williams

ctwilliams@alaska.edu

Specialty section:

This article was submitted to Behavioral and Evolutionary Ecology,

a section of the journal

Frontiers in Ecology and Evolution

Received: 19 December 2017

Accepted: 11 June 2018

Published: 03 July 2018

Citation:

Chmura HE, Glass TW and Williams CT (2018) Biologging

Physiological and Ecological

Responses to Climatic Variation: New

Tools for the Climate Change Era.

Front. Ecol. Evol. 6:92.

doi: 10.3389/fevo.2018.00092
In this mini-review, we discuss how biologging technology can be used to detect, understand, and forecast species' responses to climate change. We review studies of phenology, thermal biology, and microhabitat selection as examples to illustrate the utility of a biologging approach in terrestrial and aquatic species. These examples show that biologgers can be used to identify and predict behavioral and physiological responses to climatic variation and directional climate change, as well as to extreme weather events. While there is still considerable debate as to whether phenotypic plasticity is sufficient to facilitate species' responses to climate change or whether responses to short-term climate variability are predictive of climate change response, understanding the scope and nature of plasticity is an important step toward answering these questions. One advantage of the biologging approach is that it can facilitate the measurement of traits at the level of the individual, permitting research that investigates the degree to which physiology and behavior are plastic. As such, combining biologging with metrics of fitness can provide insight into how plasticity might confer population and species resilience to climate change. Increased use of biologgers in experimental manipulations will also yield important insight into how phenotypic flexibility allows some animals to mitigate the negative consequences of climate change. Although biologging studies to date have mostly functioned in measuring phenotypic responses to short-term climate variability, we argue that integrating biologging technology into long-term monitoring programs will be instrumental in documenting and understanding ecological responses to climate change.

Keywords: phenology, microhabitat selection, thermal biology, biologger, climate change

\section{INTRODUCTION}

Global climate change is rapidly affecting ecosystems worldwide by altering species' ranges, disrupting trophic interactions, and causing population declines. In addition to causing a rise in global mean temperatures and altering precipitation patterns (IPCC, 2014), anthropogenic climate change is affecting the frequency of climate events (e.g., El Niño and La Niña; Cai et al., 2014, 2015) and is predicted to increase the frequency and severity of extreme events (US Global Change Research Program, 2009; Holland and Bruyère, 2014). Understanding and 
predicting how these changes in the abiotic environment will alter ecosystems requires studying biological processes at multiple levels of organization, including within-individual physiological and behavioral adjustments (i.e., plasticity).

Detecting changes in species distribution and abundance with climate change requires long-term sampling. However, short-term observations of individual responses to climatic variation are often used as a proxy to predict consequences of long-term directional climate change. While there is still considerable debate regarding the relative contributions of phenotypic plasticity and evolution in climate change responses, and questions as to whether existing phenotypic plasticity is sufficient to respond to global climate change, understanding the scope of phenotypic plasticity in free-living animals is an important step toward resolving these debates (Merilä and Hendry, 2014). We argue that biologging individual responses to climate variability will likely be informative in developing predictions for climate change response, however it is important to acknowledge that climate change will affect biotic interactions across trophic levels and it is critical to take these possibilities into account when predicting species responses to climate change (Van der Putten et al., 2010). Unfortunately, direct observations of individual responses to climatic variation are often infeasible when individuals have large home ranges or use inaccessible environments. Even when individuals can be observed directly, some responses are cryptic and hard to observe using traditional methods. Although responses to manipulations of the physical or biological environment can be measured in laboratory or in semi-natural settings, these environments cannot reproduce the complexity of natural systems (Van der Putten et al., 2010). Biologging, the use of miniaturized animal-borne devices that $\log$ and/or relay data regarding an animal's movements, behavior, physiology and/or environment, offers a solution to these challenges (Rutz and Hays, 2009; Table 1). Biologgers can be deployed on free-living animals for extended periods and, when combined with monitoring of abiotic conditions, allow the detection of individual responses to biologically relevant environmental variation. With careful study design, they can also be used to quantify individual, population, and specieslevel variability in response to short-term climatic variation and long-term climate change. When deployed with experimental manipulations, they can reveal causal mechanisms. As such, they are an important tool in the climate change biologist's toolkit.

In this mini-review, we show what biologging can offer climate change research by featuring case studies of phenology, thermal biology, and microhabitat selection. We focus on how biologging technology has extended our ability to measure the responses of free-ranging subjects to climatic variability, while highlighting the few studies that have documented responses to long-term directional climate change. Finally, we suggest how biologging could be utilized to advance the discipline.

\section{PHENOLOGY}

Phenological shifts are widely documented responses to global climate change (Parmesan, 2007; Thackeray et al., 2010) and their potential to disrupt trophic interactions (Visser et al., 1998; Winder and Schindler, 2004; Post and Forchhammer,
2008) has led to concern that phenological mismatch may cause population declines (Both et al., 2010). Biologging can improve understanding of phenological responses to climate change by facilitating detection of cryptic seasonally-recurring life-cycle events (e.g., migration, hibernation, and reproduction) and study of the cues and proximate physiological mechanisms that regulate these transitions.

Novel applications of biologging are expanding as technological advances produce smaller devices with improved sensors, storage, and transmission capabilities. For example, temperature, activity, and/or GPS loggers are used to create precise timelines for implantation and/or parturition in a wide variety of mammals including brown bears (Ursus arctos) (Figure 1A; Table 1), woodland caribou (Rangifer tarandus caribou), sea otters (Enhydra lutris), and arctic ground squirrels (Urocitellus parryii) (Williams et al., 2011; Demars et al., 2013; Esslinger et al., 2014; Friebe et al., 2014; Bieber et al., 2017). GPS and light loggers can detect migration phenology in animals traveling on land, in water, or by air (Yasuda et al., 2010; Bailleul et al., 2012; Van Wijk et al., 2012; Lendrum et al., 2013; Cherry et al., 2016; Weller et al., 2016). In combination, temperature and light loggers can be used to identify dates of hibernation onset and termination in conjunction with immergence and emergence from dens or burrows (Figure 1B; Williams et al., 2011, 2017; Friebe et al., 2014). Since miniaturized biologging is a new tool, long-term phenological records collected from biologgers are sparse. However, shifts in timing have been identified in longitudinal studies in larger species (e.g., Bailleul et al., 2012; Hauser et al., 2017). For example, satellite telemetry data collected between 1993 and 2012 indicate that the Chukchi population of beluga whales (Delphinapterus leucas) are responding to later sea-ice formation by delaying autumn migration to the Bering Sea, while migration timing for the Beaufort population is not clearly related to freeze-up and remains unchanged (Hauser et al., 2017).

Biologging and environmental data can also be combined to study the environmental cues that regulate phenological timing, allowing the prediction of responses under different climate change scenarios. For example, alignment of GPS collar migration data from polar bears (Ursus maritimus) with sea-ice extent data indicates that movement from ice to land is sensitive to local changes in sea-ice cover (Cherry et al., 2016). Similarly, bird migration can be delayed by extreme cold (Briedis et al., 2017) or drought (Tøttrup et al., 2012). These studies highlight the importance of explicitly addressing the role of extreme events in predictive models that assess the impacts of gradual long-term global warming on phenology.

A robust understanding of how environmental cues shape phenology will improve predictions of the extent to which plasticity will facilitate continued phenological adjustment to climate change. For example, biologging of body temperature $\left(T_{b}\right)$ in the arctic ground squirrel has revealed sex differences in phenological flexibility: females extend hibernation in response to late spring snow whereas reproductive males do not (Figure 1B; Williams et al., 2017). Biologging has also uncovered migratory plasticity in response to environmental variation on wintering grounds (e.g., Ouwehand and Both, 2017) and along migratory corridors (e.g., Van Wijk et al., 2012). A novel analysis 
TABLE 1 | Examples of biologgers frequently used in phenological studies, the research opportunities they provide, and trade-offs to be considered in their deployment.

\begin{tabular}{|c|c|}
\hline Sensor type & Examples of use in phenology studies \\
\hline $\begin{array}{l}\text { Satellite-based } \\
\text { tracking- Global } \\
\text { Positioning Systems } \\
\text { (GPS) and Advanced } \\
\text { Research and Global } \\
\text { Observation Satellite } \\
\text { (ARGOS) }\end{array}$ & $\begin{array}{l}\text { Sea-ice affects migratory timing in beluga } \\
\text { whales (Bailleul et al., 2012; Hauser et al., } \\
\text { 2017) and polar bears (Cherry et al., } \\
\text { 2016). Snowpack/snowmelt influence } \\
\text { migration in mule deer (Lendrum et al., } \\
\text { 2013) and white-fronted geese (Van Wijk } \\
\text { et al., 2012). }\end{array}$ \\
\hline
\end{tabular}

Opportunities for use

The impact of climate change has been identified as a key question in movement studies (Hays et al., 2016). Transmitters permit data collection without animal recapture/device recovery. Access to transmitted animal location data allows visitation of clusters to assess/confirm behaviors, such as predation events (Knopff et al., 2009) and pup-rearing (Jacobs and Ausband, 2018), or to collect measurements from ephemeral habitat (e.g., sea ice or snow pack conditions).
Trade-offs

GPS has higher accuracy than ARGOS for positioning, but ARGOS and other satellite networks may be used for GPS data recovery and/ or transfer (Tomkiewicz et al., 2010). Transmitters require larger/heavier batteries, which limits deployment on small species.

Minimally-invasive external attachment approaches need to be weighed against the potential reduction of negative effects that can be achieved through implantation (Bodey et al., 2018).

Small size allows deployment on a wide variety of species, including songbirds. Light loggers can also be used to measure time above-ground or out-of-nest during daylight hours (Williams et al., 2014).
Data coarser than GPS and recapture is required to download. External attachment required. Negative effects higher for aerial foragers and devices affixed to leg bands (Costantini and Møller, 2013). Drag can be an issue, particularly for wing harness (vs. leg-loop harness; Bowlin et al., 2010).

Skin and/or subcutaneous temperature will not always reflect core temperature (Rey et al., 2016; Theimer et al., 2017).

\begin{tabular}{ll}
\hline Temperature logger & Pregnant hoary bats re-enter hibernation \\
& during late spring snow storms (Willis \\
& et al., 2006). Gestation and parturition \\
& detected in hibernating brown bear, \\
& particularly when used in combination with \\
& accelerometry (Friebe et al., 2014).
\end{tabular}

Accelerometer Timing of nocturnal migratory flights documented in songbirds (Bäckman et al., 2017). Influence of seasonal dynamics of resource availability and weather on activity patterns assessed in giant pandas (Zhang et al., 2017).
Parturition can be identified in a variety of species (Ewbank, 1969; Williams et al., 2011; Esslinger et al., 2014). Core body temperature can be used to identify unsuccessful pregnancies in lab mice (Smarr et al., 2016), though whether this approach is viable in free-living animals is unknown.
Dead reckoning theoretically possible when paired with gyroscope and magnetometers. A useful proxy for energy expenditure in terrestrial animals (Halsey et al., 2009) and can measure total and/or activity specific energy expenditures in marine mammals when linked to time activity budgets (Jeanniard-du-Dot et al., 2017).
High frequency $(10-25 \mathrm{~Hz})$ logging limits deployment duration due to battery and/or memory limitations such that implantable devices are less feasible; devices with remote download and/or inductive charge not yet available.
Frequently used in combination with

Pressure gauges (depth recorder)

Japanese flounder migrate from bay to open sea to provide optimal temperature for eggs (Yasuda et al., 2010). Spawning identified using pop-up satellite tags in halibut (Le Bris et al., 2017).

Heart rate

\author{
Seasonal changes in heart rate are caused \\ by photoperiod-induced changes of \\ endogenous heat production in graylag \\ geese (Wascher et al., 2018). Spring \\ increase in heart rate is delayed by \\ nutritional restriction in red deer (Turbill \\ et al., 2011).
} temperature and salinity sensors to remotely monitor ocean conditions (e.g., Charrassin et al., 2002).

\begin{abstract}
Although understudied, premature tag loss, reduced swimming capacity, and increased predation can be issues for pop-up satellite archival tags (Jepsen et al., 2015).
\end{abstract}

Leadless subcutaneous and intraperitoneal options (e.g., Chaise et al., 2017). Non-surgical ruminal units transmit data via UHF link to a repeater system located in a collar unit, where it is stored (Signer et al., 2010).
Frequently used to estimate daily energy expenditure but requires species-level calibration (Elliott, 2016).

\section{$-$}



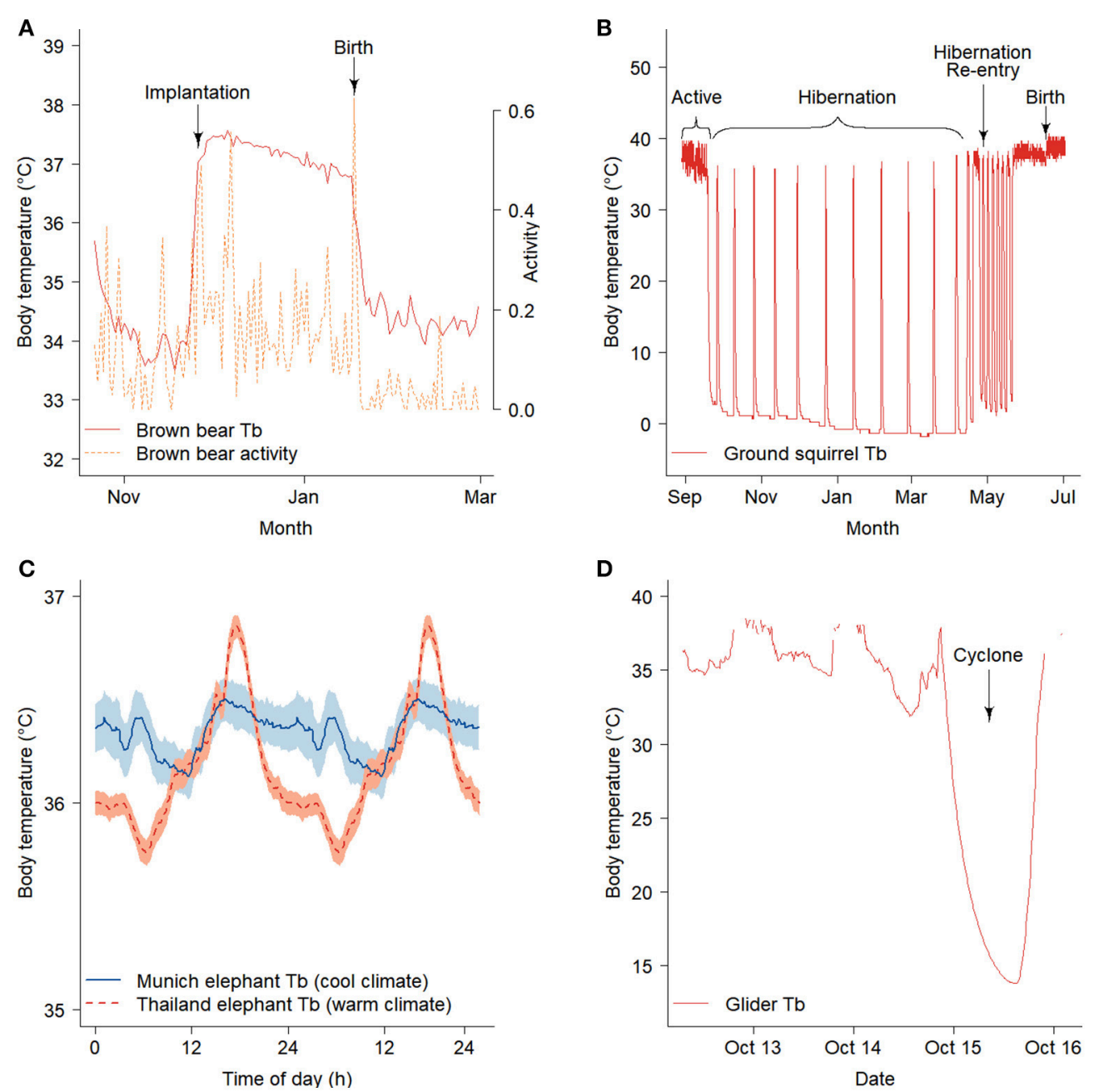

FIGURE 1 | Data collected using biologgers can potentially be used to describe climate-driven changes in the phenology and/or occurrence of reproduction. (A) Elevated body temperatures and activity indicate implantation and gestation in female brown bears with an additional a peak in activity characterizing parturition (Friebe et al., 2014). (B) Female arctic ground squirrels re-enter hibernation and show unusually late and short bouts of torpor in response to late spring snow storms resulting in delayed parturition (Williams et al., 2017). Biologgers also show the thermal response of animals to extreme events. (C) Asian elephants in a warm environment depressed body temperature during the cooler periods of the day to provide a thermal reserve for high temperatures later in the day (shading represents mean +/- s.e.m) (Weissenbock et al., 2012). (D) A sugar glider enters torpor while experiencing heavy rains and high winds during a Category 1 cyclone (Nowack et al., 2015). Figures redrawn with permission.

environment that integrates convective and radiative heat transfer on a scale relevant to an animal's microhabitat (Sinclair et al., 2016). Biologging permits the assessment of how environmental changes influence thermal performance, and consequently alter species' distributions. For example, Gannon et al. (2014) used accelerometers to gauge performance in free-living dusky flathead (Platycephalus fuscus) and showed that the temperature-dependence of performance likely limits the biogeography of this predatory fish. Using the same approach, Payne et al. (2016) demonstrated that warming tolerance is lower in species with more tropical range limits, consistent with captive studies that indicate low-latitude fishes are more sensitive to ocean warming than species that occupy higher-latitudes (Rummer et al., 2014). The shape of performance curves, however, may differ among traits and thus accelerometry alone cannot provide a complete understanding of how warming will influence biogeography. Heart rate predicts the thermal dependence of metabolism better than activity (Clark et al., 2010), suggesting a role for additional sensors in understanding how thermal limits and performance influence range shifts. Additionally, biologgers may play a crucial role in quantifying changes in thermal performance through acclimatization (i.e., physiological flexibility) and/or developmental plasticity, as well as documenting genetic variation in thermal performance (Kingsolver, 2009; GaitánEspitia et al., 2014), which are key aspects of population and species resilience to environmental change (Somero, 2010; Seebacher et al., 2015). 


\section{Endotherms: Responding to Aridity and Thermal Extremes}

Given the indirect relationship between operative temperature and metabolism in endotherms, they are thought to be somewhat buffered from the direct effects of increasing temperatures (Khaliq et al., 2014). Nevertheless, endotherms in hot arid environments may be vulnerable to climate change since increases in temperature or aridity can cause dehydration from evaporative cooling and overwhelm heat dissipation capacity. Indeed, temperature and aridity can have sublethal fitness costs and even cause direct mortality in birds and mammals (Speakman and Krol, 2010; Du Plessis et al., 2012). Biologging facilitates the measurement of the physiological and behavioral responses endotherms use to cope with high temperatures and aridity, as well as the identification of physiological limits that may shape responses to climate change.

Endotherms that maintain relatively constant $\mathrm{T}_{\mathrm{b}}$ (i.e., "homeotherms") can cope with hot arid conditions by deviating from homeothermy. Captive studies indicate that small birds reduce water loss under hot conditions by becoming hyperthermic, reducing the differential between $\mathrm{T}_{\mathrm{b}}$ and $\mathrm{T}_{\mathrm{op}}$ (reviewed in Tieleman and Williams, 1999). Although it has long been hypothesized that desert birds should facilitate passive heat loss and conserve water loss by maintaining a higher $\mathrm{T}_{\mathrm{b}}$ set-point (Withers and Williams, 1990), a compilation of laboratory data from 28 species failed to find a difference in the thermal responses of desert and non-desert species (Tieleman and Williams, 1999). However, a recent field-based biologging study by Smit et al. (2013) found that even within a species, desert-dwelling birds have higher $\mathrm{T}_{\mathrm{b}}$ set-points than individuals from a population in a wetter, semi-desert region. This highlights the utility of the biologging approach, as the physiology of animals in laboratory conditions may not be representative of physiology in nature.

Biologging studies reveal that large mammals also exhibit hyperthermia in response to high temperatures and aridity. However, unlike small mammals, large mammals benefit from a lower daily minimum $\mathrm{T}_{\mathrm{b}}$ as their larger size provides them with high thermal inertia, which creates a thermal reserve for heat storage (reviewed in Hetem et al., 2016). Later in the day, animals allow $\mathrm{T}_{\mathrm{b}}$ to rise, reducing water loss by decreasing the differential between $\mathrm{T}_{\mathrm{b}}$ and $\mathrm{T}_{\mathrm{op}}$. This pattern is particularly extreme in oryx (Oryx leucoryx), which alter $\mathrm{T}_{\mathrm{b}}$ by more than $4^{\circ} \mathrm{C}$ across the day in summer but only $1.5^{\circ} \mathrm{C}$ in winter (Ostrowski et al., 2003; Hetem et al., 2010), although it is also evident in Asian elephants (Elephas maximus; Figure 1C Weissenbock et al., 2012). In addition to changes in core $\mathrm{T}_{\mathrm{b}}$, some endotherms selectively cool regions of the brain (Midtgård, 1983; Mitchell et al., 2002; Fuller et al., 2016). Although initially demonstrated under laboratory conditions and interpreted as an adaptation to reduce the negative effects of heat stress, technological advancements that allowed blood and brain temperatures to be measured in free-living ungulates demonstrated that selective brain cooling reduces evaporative water loss, rather than preventing hyperthermia (Jessen et al., 1994; Mitchell et al., 1997; Fuller et al., 2007). In sum, biologging
$\mathrm{T}_{\mathrm{b}}$ in free-living endotherms has already provided insight into the physiological mechanisms that may allow some species to cope with increased temperatures associated with climate change. For most species, however, the physiological limits to warming are not well described and more work is needed to link utilization of heterothermy to fitness consequences in free-living populations.

\section{Endotherms: Responding to Natural Disasters}

Climate change is increasing mean temperature, as well climatic variation, leading to more frequent extreme temperature and precipitation events and natural disasters (Easterling et al., 2000; Alexander et al., 2006; Mitchell et al., 2006). Biologging has revealed that heterothermic endotherms (i.e., those that use daily torpor and/or hibernation; Ruf and Geiser, 2015) can depress their metabolism to buffer themselves from unpredictable energetic bottlenecks and/or natural disasters (Nowack et al., 2017). For example, small mammals can substantially reduce their energy consumption following late spring snowstorms, cyclones, or wildfire by entering torpor (Figure 1D; Willis et al., 2006; Nowack et al., 2015, 2016; Stawski et al., 2015). Thus, biologging indicates that facultative torpor and/or hibernation may buffer some endotherms from extreme events, analogous to how facultative migrations are used in other species (Streby et al., 2015).

\section{MICROHABITAT SELECTION}

Microclimates can provide animals with a wider range of environmental temperatures than are available on a macroclimatic scale (Scheffers et al., 2014) and utilization of microhabitats through behavioral thermoregulation may provide a means for some species to cope with climate change. Biologging allows direct measurement of an animal's experienced environment which can be compared with remotely sensed data of available habitat to investigate how microclimates influence species' ranges. For example, biologged $\mathrm{T}_{\mathrm{b}}$ and ambient temperature $\left(\mathrm{T}_{\mathrm{a}}\right)$ coupled with spatial telemetry data have revealed that habitat use at northern range limits is thermally constrained for a variety of ectotherms including wood turtles (Glyptemys insculpta; Dubois et al., 2009), loggerhead turtles (Caretta caretta; Schofield et al., 2009), and black rat snakes (Elaphe obsoleta obsolete; Blouin-Demers and Weatherhead, 2002). Such studies have the potential to reveal how microhabitat availability and selection influence species' ranges under climate change. To date however, long-term biologging studies that span wide latitudinal gradients are lacking, limiting our understanding of the factors influencing range shifts under climate change.

Ectotherms and endotherms may cope with climate change through the exploitation of spatiotemporal variation in temperature within existing home-ranges. Recent biologging studies reveal that ectotherms can partition daily and seasonal activities across thermally variable microhabitats to alter metabolic rate (e.g., Dubois et al., 2009; Harrison et al., 2016). For example, blacktip reef sharks (Carcharhinus melanopterus) 
are warmest, but least active, during the day as they move into warm water to increase rates of digestion; they peak in activity while cooling in evenings, since they forage when they have a sensory advantage under low light conditions and a thermal advantage over prey with lower thermal inertia (Papastamatiou et al., 2015). Similarly, biologging in terrestrial birds and small mammals indicates they utilize thermal refugia during periods of high heat and partition demanding activities, such as foraging, to cooler times of day when risk of dehydration is lower (e.g., Martin et al., 2015; Levy et al., 2016). Microhabitat partitioning across the day may be important as climate change is having different effects on daytime and nighttime temperatures (Easterling et al., 1997).

Microhabitat partitioning can also occur on seasonal time-scales. For example, biologgers revealed that female loggerhead turtles seek out warm water areas to accelerate egg development (Fossette et al., 2012). During winter, collarmounted temperature loggers have been used to investigate the use of nests and burrows as refugia from cold temperatures and harsh winds in red squirrels (Tamiasciurus hudsonicus; Studd et al., 2016) and opossums (Didelphis virginiana; Kanda et al., 2005). In female polar bears, biologgers were used to both identify incidences of reproductive denning and characterize the microhabitats and substrates preferred by bears for denning, the availability of which may be altered by climate change and human development (Olson et al., 2017). The continued miniaturization of biologgers will open new avenues of research. For example, while nest cavity microclimate variation is known to be an important determinant of nestling growth and survival (Catry et al., 2011; Campobello et al., 2017), biologging may prove useful in understanding how micro-climate influences adult physiology and incubation/provisioning behaviors or nestling post-fledging behavior/survival (e.g., Nord and Nilsson, 2011).

\section{A NOTE OF CAUTION}

Despite the power and potential of biologging for monitoring responses to climatic variability/change, serious consideration must be given to its potential to alter the physiological and/or behavioral parameters being measured, or negatively affect the survival and reproductive output of the tagged individual (White et al., 2013; Bodey et al., 2018). Careful consideration must be given to the size, mass, shape, buoyancy, and attachment method of the device, balancing the ecological insight that is provided with the potential deleterious effects (Wilson et al., 2015). Further, researchers need to weigh the benefits of using minimally-invasive external attachment approaches with the potential reduction in negative effects that can be achieved through implantation (Bodey et al., 2018).

\section{REFERENCES}

Alexander, L. V., Zhang, X., Peterson, T. C., Caesar, J., Gleason, B., Tank, A., et al. (2006). Global observed changes in daily climate extremes of temperature and precipitation. J. Geophys. Res. Atmosph. 111:22. doi: 10.1029/2005JD006290

\section{CONCLUSION AND FUTURE DIRECTIONS}

Biologging is broadly useful for investigating individual, population, and species responses to global climate change, including changes in the frequency of extreme climatic events. Although by no means an exhaustive review, the studies of phenology, thermal biology, and microhabitat selection that we discuss illustrate how biologging approaches can be used to uncover both physiological and behavioral responses to climate change. In cases where longitudinal data are not yet available, biologging studies have already made important contributions to the field by linking environmental variation to alterations in physiology and behavior, which facilitates predictions of climate change response. We caution, however, that predictions may fail if they are based solely on the direct effects of climate variability on individual species, as fitness is strongly influenced by interactions between species (Gilman et al., 2010).

We propose that biologging can contribute further to the field by addressing knowledge gaps and providing new methodological approaches. Research opportunities include (1) connecting biologged behavioral and physiological responses to fitness outcomes, (2) quantifying variation in behavioral and physiological responses across individuals, populations, and species for use in predictive models of plastic and evolutionary responses to climate change, and (3) increasing the use of biologgers in field-based experiments to determine the physiological mechanisms that underlie observed responses to climate variation. With the increasing miniaturization of biologgers, deployment in an ever-growing breadth of taxa, and maturation of longitudinal biologging datasets, we predict that biologging will continue to influence the study of global climate change.

\section{AUTHOR CONTRIBUTIONS}

All authors contributed to the review through development of ideas, drafting of initial text, and providing feedback for revisions. $\mathrm{HC}$ coordinated revisions amongst authors and prepared figures and $\mathrm{CW}$ initiated the project.

\section{ACKNOWLEDGMENTS}

CW acknowledges funding from the National Science Foundation grant (IOS-1558056). HC acknowledges salary support from the UC Davis Animal Behavior Graduate Group and an Institutional Development Award (IDeA) from the National Institute of General Medical Sciences of the National Institutes of Health under grant number P20GM103395. The content is solely the responsibility of the authors and does not necessarily reflect the official views of the NIH or NSF. 
Bailleul, F., Lesage, V., Power, M., Doidge, D. W., and Hammill, M. O. (2012). Migration phenology of beluga whales in a changing Arctic. Clim. Res. 53, 169-178. doi: 10.3354/cr01104

Bieber, C., Cornils, J. S., Hoelzl, F., Giroud, S., and Ruf, T. (2017). The costs of locomotor activity? Maximum body temperatures and the use of torpor during the active season in edible dormice. J. Comp. Physiol. B 187, 803-814. doi: 10.1007/s00360-017-1080-y

Blouin-Demers, G., and Weatherhead, P. J. (2002). Habitat-specific behavioural thermoregulation by black rat snakes (Elaphe obsoleta obsoleta). Oikos 97, 59-68. doi: 10.1034/j.1600-0706.2002.970106.x

Bodey, T. W., Cleasby, I. R., Bell, F., Parr, N., Schultz, A., Votier, S. C., et al. (2018). A phylogenetically controlled meta-analysis of biologging device effects on birds: Deleterious effects and a call for more standardized reporting of study data. Methods Ecol. Evol. 9, 946-955. doi: 10.1111/2041-210X.12934

Both, C., Van Turnhout, C. A. M., Bijlsma, R. G., Siepel, H., Van Strien, A. J., and Foppen, R. P. B. (2010). Avian population consequences of climate change are most severe for long-distance migrants in seasonal habitats. Proc. R. Soc. B 277, 1259-1266. doi: 10.1098/rspb.2009.1525

Bowlin, M. S., Henningsson, P., Muijres, F. T., Vleugels, R. H., Liechti, F., and Hedenström, A. (2010). The effects of geolocator drag and weight on the flight ranges of small migrants. Methods Ecol. Evol. 1, 398-402. doi: 10.1111/j.2041-210X.2010.00043.x

Briedis, M., Hahn, S., and Adamik, P. (2017). Cold spell en route delays spring arrival and decreases apparent survival in a long-distance migratory songbird. BMC Ecol. 17:8. doi: 10.1186/s12898-017-0121-4

Cai, W., Borlace, S., Lengaigne, M., Van Rensch, P., Collins, M., Vecchi, G., et al. (2014). Increasing frequency of extreme El Niño events due to greenhouse warming. Nat. Clim. Chang. 4, 111-116. doi: 10.1038/nclimate2100

Cai, W., Wang, G., Santoso, A., Mcphaden, M. J., Wu, L., et al. (2015). Increased frequency of extreme La Niña events under greenhouse warming. Nat. Clim. Chang. 5, 132-137. doi: 10.1038/nclimate2492

Campobello, D., Lindstrom, J., Di Maggio, R., and Sarà, M. (2017). An integrated analysis of micro- and macro-habitat features as a tool to detect weatherdriven constraints: a case study with cavity nesters. PLoS ONE 12:e174090. doi: 10.1371/journal.pone.0174090

Catry, I., Franco, A. M. A., and Sutherland, W. J. (2011). Adapting conservation efforts to face climate change: modifying nest-site provisioning for lesser kestrels. Biol. Cons. 144: 1111-1119. doi: 10.1016/j.biocon.2010.12.030

Chaise, L. L., Paterson, W., Laske, T. G., Gallon, S. L., McCafferty, D. J., Théry, M., et al. (2017). Implantation of subcutaneous heart rate data loggers in southern elephant seals (Mirounga leonina). Polar Biol. 40, 2307-2312. doi: 10.1007/s00300-017-2144-X

Charrassin, J. B., Park, Y. H., Maho, Y. L., and Bost, C. A. (2002). Penguins as oceanographers unravel hidden mechanisms of marine productivity. Ecol. Lett. 5, 317-319. doi: 10.1046/j.1461-0248.2002.00341.x

Cherry, S. G., Derocher, A. E., and Lunn, N. J. (2016). Habitat-mediated timing of migration in polar bears: an individual perspective. Ecol. Evol. 6, 5032-5042. doi: 10.1002/ece3.2233

Clark, T. D., Sandblom, E., Hinch, S. G., Patterson, D. A., Frappell, P. B., and Farrell, A. P. (2010). Simultaneous biologging of heart rate and acceleration, and their relationships with energy expenditure in free-swimming sockeye salmon (Oncorhynchus nerka). J. Comp. Physiol. B Biochem. Syst. Environ. Physiol. 180, 673-684. doi: 10.1007/s00360-009-0442-5

Costantini, D., and Møller, A. P. (2013). A meta-analysis of the effects of geolocator application on birds. Curr. Zool. 59, 697-706. doi: 10.1093/czoolo/59.6.697

Demars, C. A., Auger-Méth,é, M., Schlägel, U. E., and Boutin, S. (2013). Inferring parturition and neonate survival from movement patterns of female ungulates: a case study using woodland caribou. Ecol. Evol. 3, 4149-4160. doi: 10.1002/ece3.785

Deutsch, C. A., Tewksbury, J. J., Huey, R. B., Sheldon, K. S., Ghalambor, C. K., Haak, D. C., et al. (2008). Impacts of climate warming on terrestrial ectotherms across latitude. Proc. Natl. Acad. Sci. U.S.A. 105, 6668-6672. doi: $10.1073 /$ pnas.0709472105

Du Plessis, K. L., Martin, R. O., Hockey, P. A. R., Cunningham, S. J., and Ridley, A. R. (2012). The costs of keeping cool in a warming world: implications of high temperatures for foraging, thermoregulation and body condition of an arid-zone bird. Glob. Change Biol. 18, 3063-3070. doi: $10.1111 /$ j.1365-2486.2012.02778.x
Dubois, Y., Blouin-Demers, G., Shipley, B., and Thomas, D. (2009) Thermoregulation and habitat selection in wood turtles Glyptemys insculpta: chasing the sun slowly. J. Anim. Ecol. 78, 1023-1032. doi: 10.1111/j.1365-2656.2009.01555.x

Easterling, D. R., Horton, B., Jones, P. D., Peterson, T. C., Karl, T. R., Parker, D. E., et al. (1997). Maximum and minimum temperature trends for the globe. Science 277, 364-367. doi: 10.1126/science.277.5324.364

Easterling, D. R., Meehl, G. A., Parmesan, C., Changnon, S. A., Karl, T. R., and Mearns, L. O. (2000). Climate extremes: observations, modeling, and impacts. Science 289, 2068-2074. doi: 10.1126/science.289.5487.2068

Elliott, K. H. (2016). Measurement of flying and diving metabolic rate in wild animals: review and recommendations. Comp. Biochem. Physiol. A 202, 63-77. doi: 10.1016/j.cbpa.2016.05.025

Esslinger, G. G., Bodkin, J. L., Breton, A. R., Burns, J. M., and Monson, D. H. (2014). Temporal patterns in the foraging behavior of sea otters in Alaska. J. Wildlife Manage. 78, 689-700. doi: 10.1002/jwmg.701

Ewbank, R. (1969). The fall in rectal temperature seen before parturition in sheep. J. Reprod. Fertil. 19, 569-571. doi: 10.1530/jrf.0.0190569

Fossette, S., Schofield, G., Lilley, M. K. S., Gleiss, A. C., and Hays, G. C. (2012). Acceleration data reveal the energy management strategy of a marine ectotherm during reproduction. Func. Ecol. 26, 324-333. doi: 10.1111/j.1365-2435.2011.01960.x

Friebe, A., Evans, A. L., Arnemo, J. M., Blanc, S., Brunberg, S., Fleissner, G., et al. (2014). Factors affecting date of implantation, parturition, and den entry estimated from activity and body temperature in free-ranging brown bears. PLoS ONE 9:e101410. doi: 10.1371/journal.pone.0101410

Fuller, A., Meyer, L. C. R., Mitchell, D., and Maloney, S. K. (2007). Dehydration increases the magnitude of selective brain cooling independently of core temperature in sheep. Am. J. Physiol. Reg. Integr. Comp. Physio. 293, R438R446. doi: 10.1152/ajpregu.00074.2007

Fuller, A., Mitchell, D., Maloney, S. K., and Hetem, R. S. (2016). Towards a mechanistic understanding of the responses of large terrestrial mammals to heat and aridity associated with climate change. Clim. Change Resp. 3:10. doi: 10.1186/s40665-016-0024-1

Gaitán-Espitia, J. D., Bacigalupe, L. D., Opitz, T., Lagos, N. A., Timmermann, T., and Lardies, M. A. (2014). Geographic variation in thermal physiological performance of the intertidal crab Petrolisthes violaceus along a latitudinal gradient. J. Exp. Biol. 217, 4379-4386. doi: 10.1242/jeb.108217

Gannon, R., Taylor, M. D., Suthers, I. M., Gray, C. A., Van Der Meulen, D. E., Smith, J. A., et al. (2014). Thermal limitation of performance and biogeography in a free-ranging ectotherm: insights from accelerometry. J. Exp. Biol. 217, 3033-3037. doi: 10.1242/jeb.104455

Gilman, S. E., Urban, M. C., Tewksbury, J., Gilchrist, G. W., and Holt, R. D. (2010). A framework for community interactions under climate change. TREE 25, 325-331. doi: 10.1016/j.tree.2010.03.002

Halsey, L. G., Shepard, E. L. C., Quintana, F., Laich, A. G., Green, J. A., and Wilson, R. P. (2009). The relationship between oxygen consumption and body acceleration in a range of species. Comp. Biochem. Physiol. A 152, 197-202. doi: 10.1016/j.cbpa.2008.09.021

Harrison, P. M., Gutowsky, L. F., Martins, E. G., Patterson, D. A., Cooke, S. J., and Power, M. (2016). Temporal plasticity in thermal-habitat selection of burbot Lota lota a diel-migrating winter-specialist. J. Fish Biol. 88, 2111-2129. doi: $10.1111 /$ jfb.12990

Hauser, D. D. W., Laidre, K. L., Stafford, K. M., Stern, H. L., Suydam, R. S., and Richard, P. R. (2017). Decadal shifts in autumn migration timing by Pacific Arctic beluga whales are related to delayed annual sea ice formation. Glob. Change Biol. 23, 2206-2217. doi: 10.1111/gcb.13564

Hays, G. C., Ferreira, L. C., Sequeira, A. M. M., Meekan, M. G., Duarte, C. M., Bailey, H., et al. (2016). Key questions in marine megafauna movement ecology. TREE 31, 463-475. doi: 10.1016/j.tree.2016.02.015

Hetem, R. S., Maloney, S. K., Fuller, A., and Mitchell, D. (2016). Heterothermy in large mammals: inevitable or implanted? Biol. Rev. 91, 187-205. doi: $10.1111 /$ brv. 12166

Hetem, R. S., Strauss, W. M., Fick, L. G., Maloney, S. K., Meyer, L. C., Shobrak, M., et al. (2010). Variation in the daily rhythm of body temperature of free-living Arabian oryx (Oryx leucoryx): does water limitation drive heterothermy? J. Comp. Physiol. B Biochem. Syst. Environ. Physiol. 180, 1111-1119. doi: 10.1007/s00360-010-0480-z 
Holland, G., and Bruyère, C. L. (2014). Recent intense hurricane response to global climate change. Clim. Dynam. 42, 617-627. doi: 10.1007/s00382-013-1713-0

IPCC (2014). Climate Change 2014: "Synthesis Report," Contribution of Working Groups, I, II and III to the Fifth Assessment Report of the Intergovernmental Panel on Climate Change, eds R. K. Pachauri and L. A. Meyer (Geneva: Core Writing Team; IPCC), 151.

Jacobs, C. E., and Ausband, D. E. (2018). Pup-rearing habitat use in a harvested carnivore. J. Wildl. Manage. 82, 802-809. doi: 10.1002/jwmg.21434

Jeanniard-du-Dot, T., Guinet, C., Arnould, J. P., Speakman, J. R., and Trites, A. W. (2017). Accelerometers can measure total and activity-specific energy expenditures in free-ranging marine mammals only if linked to time-activity budgets. Func. Ecol. 31, 377-386. doi: 10.1111/1365-2435.12729

Jepsen, N., Thorstad, E. B., Havn, T., and Lucas, M. C. (2015). The use of external electronic tags on fish: an evaluation of tag retention and tagging effects. Anim. Biotelem. 3:49. doi: 10.1186/s40317-015-0086-z

Jessen, C., Laburn, H. P., Knight, M. H., Kuhnen, G., Goelst, K., and Mitchell, D. (1994). Blood and brain temperatures of free-ranging black wildebeest in their natural environment. Am. J. Physiol. Regul. Integr. Comp. Physiol. 267, R1528-1536. doi: 10.1152/ajpregu.1994.267.6.R1528

Kanda, L. L., Fuller, T. K., and Friedland, K. D. (2005). Temperature sensor evaluation of opossum winter activity. Wildl. Soc. Bull. 33, 1425-1431. doi: 10. 2193/0091-7648(2005)33[1425:TSEOOW]2.0.CO;2

Khaliq, I., Hof, C., Prinzinger, R., Böhning-Gaese, K., and Pfenninger, M. (2014). Global variation in thermal tolerances and vulnerability of endotherms to climate change. Proc. Biol. Sci. 281:20141097. doi: 10.1098/rspb.201 4.1097

Kingsolver, J. G. (2009). The well-temperatured biologist. (American Society of Naturalists Presidential Address). Am. Nat. 174, 755-768. doi: 10.1086/6 48310

Knopff, K. H., Knopff, A. A., Warren, M. B., and Boyce, M. S. (2009). Evaluating global positioning system telemetry techniques for estimating cougar predation parameters. J. Wildl. Manage. 73, 586-597. doi: 10.2193/2008-294

Le Bris, A., Fisher, J. A., Murphy, H. M., Galbraith, P. S., Castonguay, M., Loher, T., et al. (2017). Migration patterns and putative spawning habitats of Atlantic halibut (Hippoglossus hippoglossus) in the Gulf of St. Lawrence revealed by geolocation of pop-up satellite archival tags. ICES J. Mar. Sci. 75, 135-147. doi: 10.1093/icesjms/fsx098

Lendrum, P. E., Anderson, C. R., Monteith, K. L., Jenks, J. A., and Bowyer, R. T. (2013). Migrating mule deer: effects of anthropogenically altered landscapes. PLoS ONE 8:e64548. doi: 10.1371/journal.pone.0064548

Levy, O., Dayan, T., Porter, W. P., and Kronfeld-Schor, N. (2016). Foraging activity pattern is shaped by water loss rates in a diurnal desert rodent. Am. Nat. 188, 205-218. doi: $10.1086 / 687246$

Martin, R. O., Cunningham, S. J., and Hockey, P. A. R. (2015). Elevated temperatures drive fine-scale patterns of habitat use in a savanna bird community. Ostrich 86, 127-135. doi: 10.2989/00306525.2015.1029031

Merilä, J., and Hendry, A. P. (2014), Climate change, adaptation, and phenotypic plasticity: the problem and the evidence. Evol. Appl. 7, 1-14. doi: 10.1111/eva.12137

Midtgård, U. (1983). Scaling of the brain and the eye cooling system in birds: a morphometric analysis of the Rete ophthalmicum. J. Exp. Zool. 225, 197-207. doi: $10.1002 /$ jez.1402250204

Mitchell, D., Maloney, S. K., Jessen, C., Laburn, H. P., Kamerman, P. R., and Mitchell, G. (2002). Adaptive heterothermy and selective brain cooling in aridzone mammals. Comp. Biochem. Physiol. B,. Biochem. Mol. Biol. 131, 571-585. doi: 10.1016/S1096-4959(02)00012-X

Mitchell, D., Maloney, S. K., Laburn, H. P., Knight, M. H., Kuhnen, G., and Jessen, C. (1997). Activity, blood temperature and brain temperature of free-ranging springbok. J. Comp. Physiol. B,. Biochem. Syst. Environ. Physiol. 167, 335-343. doi: $10.1007 / \mathrm{s} 003600050082$

Mitchell, J. F. B., Lowe, J., Wood, R. A., and Vellinga, M. (2006). Extreme events due to human-induced climate change. Phil. Trans. R. Soc. A 364, 2117-2133. doi: 10.1098/rsta.2006.1816

Nord, A., and Nilsson, J. A. (2011). Incubation temperature affects growth and energy metabolism in blue tit nestlings. Am. Nat. 178, 639-651. doi: $10.1086 / 662172$

Nowack, J., Cooper, C. E., and Geiser, F. (2016). Cool echidnas survive the fire. Proc. R. Soc. B 283:20160382. doi: 10.1098/rspb.2016.0382
Nowack, J., Rojas, A. D., Körtner, G., and Geiser, F. (2015). Snoozing through the storm: torpor use during a natural disaster. Sci. Rep. 5:11243. doi: $10.1038 /$ srep 11243

Nowack, J., Stawski, C., and Geiser, F. (2017). More functions of torpor and their roles in a changing world. J. Comp. Physiol. B Biochem. Syst. Environ. Physiol. 187, 889-897. doi: 10.1007/s00360-017-1100-y

Olson, J. W., Rode, K. D., Eggett, D., Smith, T. S., Wilson, R. R., Durner, G. M., et al. (2017). Collar temperature sensor data reveal long-term patterns in southern Beaufort Sea polar bear den distribution on pack ice and land. Mar. Ecol. Prog. Ser. 564, 211-224. doi: 10.3354/meps12000

Ostrowski, S., Williams, J. B., and Ismael, K. (2003). Heterothermy and the water economy of free-living Arabian oryx (Oryx leucoryx). J. Exp. Biol. 206, 1471-1478. doi: 10.1242/jeb.00275

Ouwehand, J., and Both, C. (2017). African departure rather than migration speed determines variation in spring arrival in pied flycatchers. J. Anim. Ecol. 86, 88-97. doi: 10.1111/1365-2656.12599

Paaijmans, K. P., Heinig, R. L., Seliga, R. A., Blanford, J. I., Blanford, S., Murdock, C. C., et al. (2013). Temperature variation makes ectotherms more sensitive to climate change. Glob. Change Biol. 19, 2373-2380. doi: 10.1111/gcb.12240

Papastamatiou, Y. P., Watanabe, Y. Y., Bradley, D., Dee, L. E., Weng, K., Lowe, C. G., et al. (2015). Drivers of daily routines in an ectothermic marine predator: hunt warm, rest warmer? PLoS ONE 10:e0127807. doi: 10.1371/journal.pone. 0127807

Parmesan, C. (2007). Influences of species, latitudes and methodologies on estimates of phenological response to global warming. Glob. Change Biol. 13, 1860-1872. doi: 10.1111/j.1365-2486.2007.01404.x

Payne, N. L., Smith, J. A., Van Der Meulen, D. E., Taylor, M. D., Watanabe, Y. Y., Takahashi, A., et al. (2016). Temperature dependence of fish performance in the wild: links with species biogeography and physiological thermal tolerance. Func. Ecol. 30, 903-912. doi: 10.1111/1365-2435.12618

Post, E., and Forchhammer, M. C. (2008). Climate change reduces reproductive success of an Arctic herbivore through trophic mismatch. Phil. Trans. R. Soc. B 363, 2369-2375. doi: 10.1098/rstb.2007.2207

Rey, B., Fuller, A., Hetem, R. S., Lease, H. M., Mitchell, D., and Meyer, L. C. (2016). Microchip transponder thermometry for monitoring core body temperature of antelope during capture. J. Thermal. Biol. 55, 47-53. doi: 10.1016/j.jtherbio.2015.11.010

Ruf, T., and Geiser, F. (2015). Daily torpor and hibernation in birds and mammals. Biol. Rev. 90, 891-926. doi: 10.1111/brv.12137

Rummer, J. L., Couturier, C. S., Stecyk, J. A. W., Gardiner, N. M., Kinch, J. P., Nilsson, G. E., et al. (2014). Life on the edge: thermal optima for aerobic scope of equatorial reef fishes are close to current day temperatures. Glob. Change Biol. 20, 1055-1066. doi: 10.1111/gcb.12455

Rutz, C., and Hays, G. C. (2009). New frontiers in biologging science. Biol. Lett. 5, 289-292. doi: 10.1098/rsbl.2009.0089

Scheffers, B. R., Edwards, D. P., Diesmos, A., Williams, S. E., and Evans, T. A. (2014). Microhabitats reduce animal's exposure to climate extremes. Glob. Change Bio. 20, 495-503. doi: 10.1111/gcb.12439

Schmaljohann, H., and Both, C. (2017). The limits of modifying migration speed to adjust to climate change. Nat. Clim. Chang. 7, 573-576. doi: $10.1038 /$ nclimate3336

Schofield, G., Bishop, C. M., Katselidis, K. A., Dimopoulos, P., Pantis, J. D., and Hays, G. C. (2009). Microhabitat selection by sea turtles in a dynamic thermal marine environment. J. Anim. Ecol. 78, 14-21. doi: 10.1111/j.1365-2656.2008.01454.x

Seebacher, F., White, C. R., and Franklin, C. E. (2015). Physiological plasticity increases resilience of ectothermic animals to climate change. Nat. Clim. Chang. 5, 61-66. doi: 10.1038/nclimate2457

Signer, C., Ruf, T., Schober, F., Fluch, G., Paumann, T., and Arnold, W. (2010). A versatile telemetry system for continuous measurement of heart rate, body temperature and locomotor activity in free-ranging ruminants. Methods Ecol. Evol. 1, 75-85. doi: 10.1111/j.2041-210X.2009.00010.x

Sinclair, B. J., Marshall, K. E., Sewell, M. A., Levesque, D. L., Willett, C. S., Slotsbo, S., et al. (2016). Can we predict ectotherm responses to climate change using thermal performance curves and body temperatures? Ecol. Lett. 19, 1372-1385. doi: 10.1111/ele.12686

Smarr, B. L., Zucker, I., and Kriegsfeld, L. J. (2016). Detection of successful and unsuccessful pregnancies in mice within hours of pairing through frequency 
analysis of high temporal resolution core body temperature data. PLoS ONE 11:e0160127. doi: 10.1371/journal.pone.0160127

Smit, B., Harding, C. T., Hockey, P. A., and Mckechnie, A. E. (2013). Adaptive thermoregulation during summer in two populations of an arid-zone passerine. Ecology 94, 1142-1154. doi: 10.1890/12-1511.1

Somero, G. N. (2010). The physiology of climate change: how potentials for acclimatization and genetic adaptation will determine 'winners' and 'losers'. J. Exp. Biol. 213, 912-920. doi: 10.1242/jeb.037473

Speakman, J. R., and Krol, E. (2010). Maximal heat dissipation capacity and hyperthermia risk: neglected key factors in the ecology of endotherms. J. Anim. Ecol. 79, 726-746. doi: 10.1111/j.1365-2656.2010.01689.x

Stawski, C., Körtner, G., Nowack, J., and Geiser, F. (2015). The importance of mammalian torpor for survival in a post-fire landscape. Biol. Lett. 11:20150134 doi: $10.1098 / \mathrm{rsbl} .2015 .0134$

Streby, H. M., Kramer, G. R., Peterson, S. M., Lehman, J. A., Buehler, D. A., and Andersen, D. E. (2015). Tornadic storm avoidance behavior in breeding songbirds. Cur. Biol. 25, 98-102. doi: 10.1016/j.cub.2014.10.079

Studd, E. K., Boutin, S., Mcadam, A. G., and Humphries, M. M. (2016). Nest attendance of lactating red squirrels (Tamiasciurus hudsonicus): influences of biological and environmental correlates. J. Mammal. 97, 806-814. doi: 10.1093/jmammal/gyw010

Thackeray, S. J., Sparks, T. H., Frederiksen, M., Burthe, S., Bacon, P. J., Bell, J. R., et al. (2010). Trophic level asynchrony in rates of phenological change for marine, freshwater and terrestrial environments. Glob. Change Biol. 16, 3304-3313. doi: 10.1111/j.1365-2486.2010.02165.x

Theimer, T. C., Williams, C. T., Johnson, S. R., Gilbert, A. T., Bergman, D. L., and Buck, C. L. (2017). Den use and heterothermy during winter in free-living, suburban striped skunks. J. Mammal. 98, 867-873. doi: 10.1093/jmammal/gyx009

Tieleman, B. I., and Williams, J. B. (1999). The role of hyperthermia in the water economy of desert birds. Physiol. Biochem. Zool. 72, 87-100. doi: $10.1086 / 316640$

Tomkiewicz, S. M., Fuller, M. R., Kie, J. G., and Bates, K. K. (2010). Global positioning system and associated technologies in animal behaviour and ecological research. Phil. Trans. B 365, 2163-2176. doi: 10.1098/rstb.2010.0090

Tøttrup, A. P., Klaassen, R. H. G., Kristensen, M. W., Strandberg, R., Vardanis, Y., Lindstrom, A., et al. (2012). Drought in Africa caused delayed arrival of European songbirds. Science 338, 1307-1307. doi: 10.1126/science. 1227548

Turbill, C., Ruf, T., Mang, T., and Arnold, W. (2011). Regulation of heart rate and rumen temperature in red deer: effects of season and food intake. J. Exp. Biol. 214, 963-970. doi: 10.1242/jeb052282

US Global Change Research Program (2009). Global Climate Change Impacts in the United States: A State of Knowledge Report. Cambridge; New York, NY: Cambridge University Press.

Van der Putten, W. H., Macel, M., and Visser, M. E. (2010). Predicting species distribution and abundance responses to climate change: why it is essential to include biotic interactions across trophic levels. Philos. Trans. R. Soc. B Biol. Sci. 365, 2025-2034. doi: 10.1098/rstb.2010.0037

Van Wijk, R. E., Kolzsch, A., Kruckenberg, H., Ebbinge, B. S., Muskens, G., and Nolet, B. A. (2012). Individually tracked geese follow peaks of temperature acceleration during spring migration. Oikos 121, 655-664. doi: 10.1111/j.1600-0706.2011.20083.x

Visser, M. E., Van Noordwijk, A. J., Tinbergen, J. M., and Lessells, C. M. (1998). Warmer springs lead to mistimed reproduction in great tits (Parus major). Proc. R. Soc. B 265, 1867-1870. doi: 10.1098/rspb.1998.0514
Wascher, C. A., Kotrschal, K., and Arnold, W. (2018). Free-living greylag geese adjust their heart rates and body core temperatures to season and reproductive context. Sci. Rep. 8:2142. doi: 10.1038/s41598-018-20655-Z

Weissenbock, N. M., Arnold, W., and Ruf, T. (2012). Taking the heat: thermoregulation in Asian elephants under different climatic conditions. J. Comp. Physiol. B,. Biochem. Syst. Environ. Physiol. 182, 311-319. doi: 10.1007/s00360-011-0609-8

Weller, T. J., Castle, K. T., Liechti, F., Hein, C. D., Schirmacher, M. R., and Cryan, P. M. (2016). First direct evidence of long-distance seasonal movements and hibernation in a migratory bat. Sci. Rep. 6:34585. doi: 10.1038/srep34585

White, C. R., Cassey, P., Schimpf, N. G., Halsey, L. G., Green, J. A., and Portugal, S.J. (2013). Implantation reduces the negative effects of bio-logging devices on birds. J. Exp. Biol. 216, 537-542. doi: 10.1242/jeb.076554

Williams, C. T., Buck, C. L., Sheriff, M. J., Richter, M. M., Krause, J. S., and Barnes, B. M. (2017). Sex-dependent phenological plasticity in an arctic hibernator. Am. Nat. 190, 854-859. doi: 10.1086/694320

Williams, C. T., Sheriff, M. J., Schmutz, J. A., Kohl, F., Toien, O., Buck, C. L., et al. (2011). Data logging of body temperatures provides precise information on phenology of reproductive events in a free-living arctic hibernator. J. Comp. Physiol. B Biochem. Syst. Environ. Physiol. 181, 1101-1109. doi: 10.1007/s00360-011-0593-z

Williams, C. T., Wilsterman, K., Kelley, A. D., Breton, A. R., Stark, H., Humphries, M. M., et al. (2014). Light loggers reveal weather-driven changes in the daily activity patterns of arboreal and semifossorial rodents. J. Mammal. 95, 1230-1239. doi: 10.1644/14-MAMM-A-062

Willis, C. K., Brigham, R. M., and Geiser, F. (2006). Deep, prolonged torpor by pregnant, free-ranging bats. Naturwissenschaften 93, 80-83. doi: 10.1007/s00114-005-0063-0

Wilson, A. D., Wikelski, M., Wilson, R. P., and Cooke, S. J. (2015). Utility of biological sensor tags in animal conservation. Conserv. Biol. 29, 1065-1075. doi: $10.1111 /$ cobi. 12486

Winder, M., and Schindler, D. E. (2004). Climate change uncouples trophic interactions in an aquatic ecosystem. Ecology 85, 2100-2106. doi: 10.1890/04-0151

Withers, P. C., and Williams, J. B. (1990). Metabolic and respiratory physiology of an arid-adapted australian bird, the spinifex pigeon. Condor 92, 961-969. doi: $10.2307 / 1368732$

Yasuda, T., Kawabe, R., Takahashi, T., Murata, H., Kurita, Y., Nakatsuka, N., et al. (2010). Habitat shifts in relation to the reproduction of Japanese flounder Paralichthys olivaceus revealed by a depth-temperature data logger. J. Exp. Mar. Biol. Ecol. 385, 50-58. doi: 10.1016/j.jembe.2010.02.001

Zhang, J., Hull, V., Ouyang, Z., He, L., Connor, T., Yang, H., et al. (2017). Modeling activity patterns of wildlife using time-series analysis. Ecol. Evol. 7, 2575-2584. doi: $10.1002 /$ ece 3.2873

Conflict of Interest Statement: The authors declare that the research was conducted in the absence of any commercial or financial relationships that could be construed as a potential conflict of interest.

Copyright (c) 2018 Chmura, Glass and Williams. This is an open-access article distributed under the terms of the Creative Commons Attribution License (CC BY). The use, distribution or reproduction in other forums is permitted, provided the original author(s) and the copyright owner(s) are credited and that the original publication in this journal is cited, in accordance with accepted academic practice. No use, distribution or reproduction is permitted which does not comply with these terms. 